\title{
SIMULATION AND EXPERIMENTAL STUDY IN THE PROCESS OF WAVE ENERGY CONVERSION
}

\author{
Wei Zhang, Ph. D., \\ Yanjun Liu, Ph. D., \\ Mechanical Engineering Institute, Shandong University, \\ Jinan, Shandong, China
}

\begin{abstract}
This article introduces the operating principle of the wave energy device and makes AMEsim simulated analysis in the influence of the amplitude and period of the wave on the output efficient. By using the result of the simulation to optimize design, the article puts forwards a kind of suitable control technology which based on the disclosed amplitude and period of the wave to control the check valve, invoking the motor in different levels of efficiency. This kind of technology aims to solve the problem which includes low efficiency and high start wave of the wave energy device. The result is verified by the physical experiment, which lays the foundation for the implementation of marine engineering. The established methods of simulation model and analysis results are expected to be useful to designing and manufacturing of wave energy converter
\end{abstract}

Keywords: Wave energy converter, Suitable control technology, Experimental verification

\section{INTRODUCTION}

With the gradual depletion of oil or other fossil fuels and the concern of global climate change caused by greenhouse gas emissions [1], low-carbon and energy saving, development and utilization of renewable energy is becoming the theme of world energy development [2]. The ocean has tremendous energy. The development and utilization of ocean energy is the trend of world energy development. The use of ocean power can replace fossil energy that can cause environmental pollution, which has important economic and social significance [3]. Wave power generation technology which belongs to ocean power generation technology converts wave energy into electrical energy by wave energy absorbing and conversion devices [4].

The point absorbers possess a large power-to-volume ratio implying a large ratio of absorbed power to the submerged buoy volume compared to other types of absorbers [5]. They are also attractive in terms of easy modelling because the scattered wave field can be neglected and forces on the body are only due to incident waves. A series of studies by Falnes and, Evans (1981) [6] French and Bracewell (1986) [7], Pizer (1993) [8], Vantorre et al. (2004) [9], Babarit et al. (2004) [10] and others have carried out on these devices both in regular and irregular waves.

The difficulties lie in wave energy development process is how to achieve efficient and stable conversion. Due to instability caused by waves, conversion devices' operation condition always out of design condition in a long term, apart from this. Moreover, the instability of energy transfer systems also 
limits the efficiency of power generating system. Therefore, the permanent goal of wave energy research is to improve the conversion rate and stability [11].

Wave power generation devices which adopt hydraulic transmission transfer wave energy into hydraulic energy, then transfers hydraulic energy into electrical energy of power generator by using hydraulic motors. The way of hydraulic drive system replacing the traditional mechanical transmission can improve the stability of the systematic output electric power [12].

The wave amplitude and period in wave power generation system directly determine the energy efficiency of the system output [13]. This article centers on the the influence of hydraulic system of single float power generate equipment and the wave amplitude and period on power generation efficiency.

The first section: the introduction of operating principle of hydraulic system; the second section: a theoretical estimation on the movement displacement of the object according to the actual oceanic conditions. The third section is simulation analysis: build simulation model, then design simulation parameters based on theoretical calculations and analyze the output pressure, flow and efficiency of the single float wave power device which influenced by wave height and period. The forth section: optimize the system design according to the simulation results and propose the adaptive control technology of hydraulic system, solve the low efficiency of power generation and the low utilization rate of wave energy. The fifth section: build the land bench, verify the simulation results; The section sixth: reach a conclusion.

Previous papers were studied from the theoretical to the semi-physical experiments and propose a new technique based on simulation results, which has an important referential value to improve the stability and efficiency of the power generation.

\section{WORK PRINCIPLE AND COMPOSITION OF WAVE ENERGY CONVERTER}

Fig. 1 is a new wave energy device. This device includes wave energy conversion systems, energy transfer system, power consumption system, control and measurement system. Using the hydraulic system as energy transmission can improve the stability of output electric power.

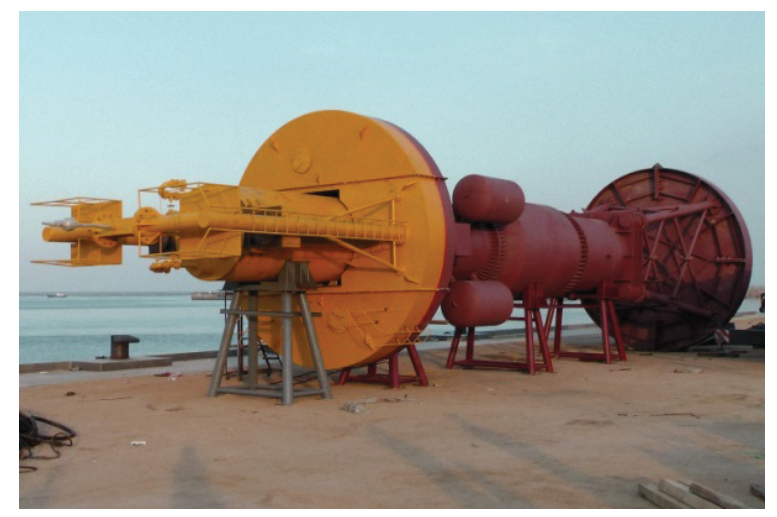

Fig. 1. Wave energy power generation device

\section{HYDRAULIC TRANSMISSION PRINCIPLE}

Hydraulic drive system is the key to ensure stability of output power. It can buffer irregular shock wave energy. Wave energy collection system converts wave energy to mechanical energy of the float, the movement of the float converts mechanical energy into hydraulic energy, the hydraulic motor rotated by hydraulic drive system which motivates the power generator, and then output the stable electric power. Fig. 2 is a schematic diagram of the hydraulic drive system. Increasing the output energy efficiency of the hydraulic system by double rod hydraulic cylinders, meanwhile ensure the hydraulic energy discharge when the float downward or upward. Using a check to valve constitute a hydraulic rectifier module, which ensure that the hydraulic output for the same direction and at the same time keep the hydraulic motor rotation direction stay the same. By the reasonable match of the various parts of the hydraulic drive system parameters can make the output power more stable.

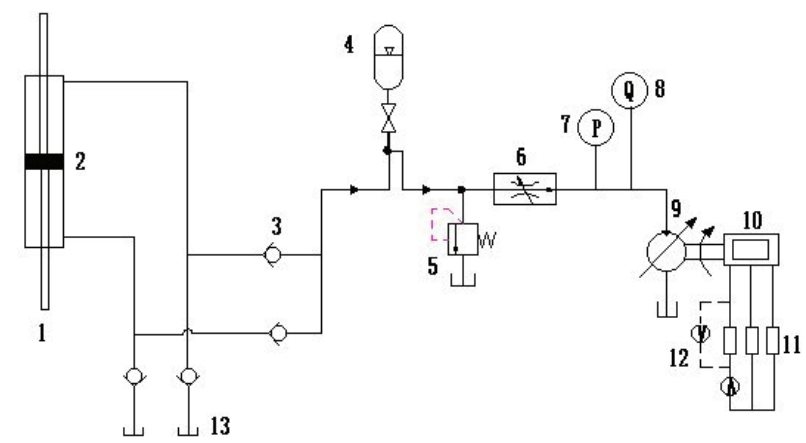

1. hydraulic rod 2. hydraulic cylinder 3. one-way valve 4. accumulator 5. relief valve 6. speed regulation valve 7. pressure sensor 8 . flow sensor 9 . motor 10. generator 11 .loads 12. voltage sensor 13. oil tank

Fig. 2. Working principle of hydraulic transmission system

\section{ESTABLISHMENT OF MATHEMATICAL MODEL}

In order to study the influence of wave amplitude and period on the operating condition, the first step is to build a math module to estimate the displacement of the float in the actual situation [14].

Under normal conditions, we can describe displacement of the vertical cylindrical float downs System $\mathrm{z}$ as the formula below:

$$
\begin{aligned}
Z=\frac{\left(F_{0} / \rho g A_{w p}\right) \cos \left(w t+\gamma-\sigma_{z}\right)}{\sqrt{\left(1-w^{2} / w_{z}^{2}\right)^{2}+\left(2 \Delta_{z} w / w_{z}\right)^{2}}} \\
=Z_{0} \cos \left(w t+\gamma-\sigma_{z}\right)
\end{aligned}
$$


In the formula:

$F_{0}$ - amplitude of the wave force;

$m$ - mass of float;

$m_{w}$ - additional mass, $m_{w}=\rho \frac{D^{3}}{6}$;

$D$ - float diameter;

$A_{w p}$ - water cut area, $A_{w p}=\frac{\pi D^{2}}{4}$;

$w_{z}$ - rolling natural frequency, $w_{z}=\sqrt{\frac{\rho g A_{w p}}{m+m_{w}}}$.

According to the formula: $w_{z}$ is related to $A_{w p}$, after the shape of the float is chosen, $w_{z}$ is ensured. Therefore, determines the frequency ratio $w / w_{z}$, then ensure $/\left(F_{0} / \rho g A_{w p}\right)$ according Fig. 3, In this case, if the amplitude of the wave force $F_{0}$ is determined, the range of motion $z_{0}$ can be determined.

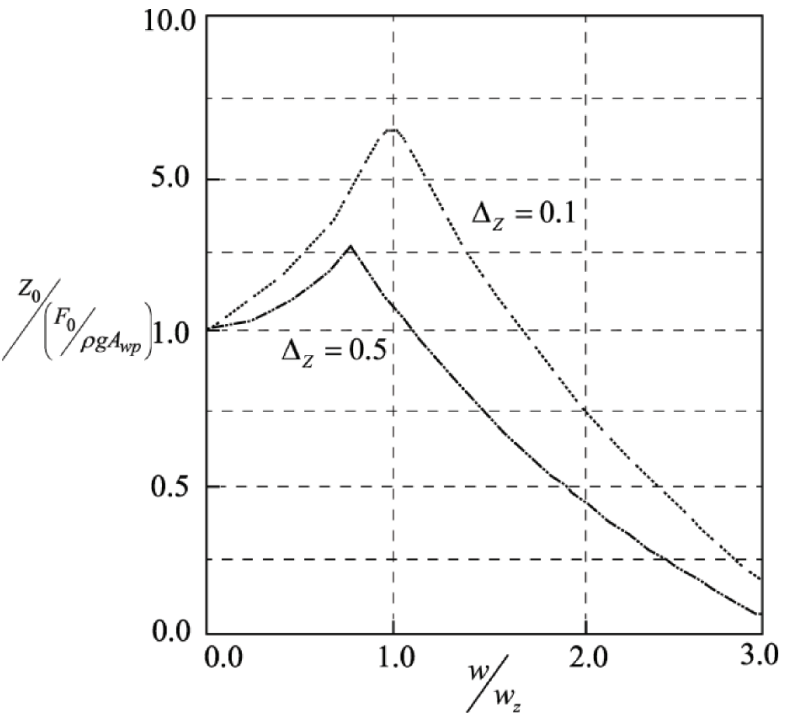

Fig. 3. Amplification coefficient of damping ratio changing with frequency ratio

According to the Froude-Krylov assumption theory that acting on the submerged body of a vertical wave force is:

$$
F_{v}=C_{V} \iint_{S} P_{z} d s
$$

When the $H / 2 R$ value is small, viscous forces are negligible, the vertical wave force is:

$$
\begin{aligned}
& F_{V}=C_{v} \iint_{S} P n_{z} \mathrm{~d} s \\
& =2 C_{v} \int_{0}^{R} \int_{0}^{\pi} P \cdot r \mathrm{~d} \theta \mathrm{d} r \\
& =C_{v} \rho g \pi H \frac{\cosh k(h-d(t))}{\cosh k h} \cos \omega t \int_{0}^{R} J_{0}(k r) r d r \\
& =C_{v} \rho g \pi H R J_{1}(k R) \frac{\cosh k(h-d(t))}{k \cdot \cosh k h} \cos \omega t \\
& =F_{0} \cdot \cos \omega t
\end{aligned}
$$

In the formula:

$$
\begin{aligned}
& k \text { - number of waves, } k=\frac{2 \pi}{\lambda} ; \\
& C_{v} \text { - diffraction coefficient; } \\
& \mathrm{H} \text {---- wave height; } \\
& \mathrm{h} \text {---- water depth; } \\
& \mathrm{R} \text {----float radius. }
\end{aligned}
$$

According to local meteorological and hydrological data, the wave height of the waves of sea trials focused between 1 $\mathrm{m}$ to $2 \mathrm{~m}$, the wave period mainly between $2 \mathrm{~s}$ and $8 \mathrm{~s}$. The condition of the trial ocean is shown in the Tab. 1.

Tab. 1. Experimental condition parameters

\begin{tabular}{ccc}
\hline Physical quantities & Symbol & Value \\
\hline Depth & $\mathrm{h}$ & $20 \mathrm{~m}$ \\
Wave height & $\mathrm{H}$ & $1-2 \mathrm{~m}$ \\
Period & $\mathrm{T}$ & $2-8 \mathrm{~S}$ \\
$\begin{array}{c}\text { Total weight of the } \\
\text { moving part of float }\end{array}$ & $m_{z}$ & $15000 \mathrm{~kg}$ \\
Float radius & $\mathrm{R}$ & $1.5 \mathrm{~m}$ \\
Density of sea water & $\rho$ & $1025 \mathrm{~kg} / \mathrm{m}^{3}$ \\
\hline
\end{tabular}

Substituting the above parameters into the formula can achieve:

$$
\begin{gathered}
m_{w}=\rho \frac{D^{3}}{6}=\frac{1025 \times 3^{3}}{6}=4612.5 \mathrm{~kg} \\
m_{z}=15000 \mathrm{~kg} \\
A_{w p}=\frac{\pi D^{2}}{4}=\frac{3^{2} \times 3.14}{4}=7.065 \mathrm{~m}^{2}
\end{gathered}
$$

$$
\begin{gathered}
w_{z}=\sqrt{\frac{\rho g A_{w p}}{m_{z}+m_{w}}}=\sqrt{\frac{1025 \times 9.8 \times 7.065}{15000+4612.5}}=1.902 \mathrm{~kg} \\
w=\frac{2 \pi}{T}=\frac{2 \times 3.14}{5}=1.25 \\
\frac{w}{w_{z}}=\frac{1.04}{3.92}=0.55
\end{gathered}
$$

Take $\Delta_{Z}=0.5$,from fig 3 can achieve:

$$
Z_{0} /\left(F_{0} / \rho g A_{w p}\right)^{=1.5}
$$

Thus:

$$
Z_{0}=\frac{1.5 F_{0}}{\rho g A_{w p}}=\frac{1.5 \times F_{0}}{1025 \times 9.8 \times 7.065}
$$


According wave condition ranges from 1 to $2 \mathrm{~m}$, the wave height is taken respectively $1 \mathrm{~m}, 1.5 \mathrm{~m}, 2 \mathrm{~m}$, corresponding to the movement of the float displacement $Z_{0}$ is calculated, the calculation results is as below in Tab. 2 .

Tab. 2. The calculation results

\begin{tabular}{|c|c|c|c|c|c|}
\hline Calculation & $\lambda$ & $\mathrm{k}$ & $\mathrm{C}_{\mathrm{v}}$ & $\mathrm{F}_{0} / \mathrm{N}$ & $\mathrm{Z}_{0}$ \\
\hline $\mathrm{H}=1 \mathrm{~m}$ & 15.23 & 0.41 & 1.33 & 16218 & 0.34 \\
\hline $\mathrm{H}=1.5 \mathrm{~m}$ & 18.40 & 0.34 & 1.12 & 34646 & 0.732 \\
\hline $\mathrm{H}=2 \mathrm{~m}$ & 20.94 & 0.30 & 1.12 & 65880 & 1.39 \\
\hline
\end{tabular}

According to the theoretical calculations and actual oceanic conditions, this article selects float displacement $Z_{0}$ as $0.5 \mathrm{~m}$, $0.7 \mathrm{~m}, 1.0 \mathrm{~m}$ and period as $2.5 \mathrm{~s}, 5 \mathrm{~s}$, and $7.5 \mathrm{~s}$.

\section{SIMULATION AND ANALYSIS}

\section{THE ESTABLISHMENT OF MODEL}

Fig. 4 is a principle diagram based on hydraulic drive system to build a simulation model by AMESim. We can simulate condition of float in the designed term by inputting the amplitude and period of the signal.

(C)

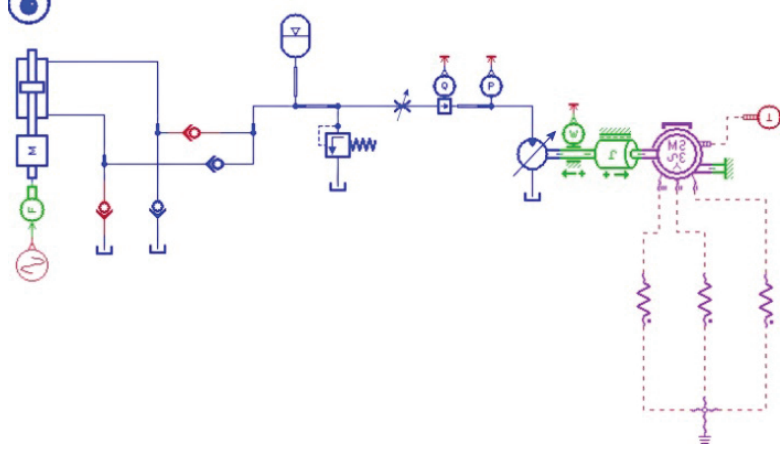

Fig. 4. Simulation model

The main parameters of model are shown in Tab. 3:

Tab. 3. Main parameters of the model

\begin{tabular}{lc}
\hline \multicolumn{1}{c}{ Main model } & Settings parameters \\
\hline Piston diameter & $180 \mathrm{~mm}$ \\
Diameter of piston pole & $140 \mathrm{~mm}$ \\
Hydraulic cylinder stroke & $5 \mathrm{~m}$ \\
Hydraulic motor & speed: $1000 \mathrm{rev} / \mathrm{min} ;$ \\
& displacement: $160 \mathrm{~mL} / \mathrm{r}$ \\
Electrical generators & three-phase permanent \\
& synchronous generators \\
Coefficient of viscous friction & $0.1 \mathrm{Nm} /($ rev/min) \\
\hline
\end{tabular}

\section{SIMULATION ANALYSIS ON DIFFERENT WAVE PERIOD}

In order to study the affect of wave period on the power output of a wave power generation system, using the simulation model of AMESim to make detailed analysis [15-17]. Setting the amplitude of float motion as $1 \mathrm{~m}$ and the working period as $2.5 \mathrm{~s}, 5 \mathrm{~s}, 7.5 \mathrm{~s}$ to run the model, at this point the motor output pressure flow curve shown in Fig. 5-7:

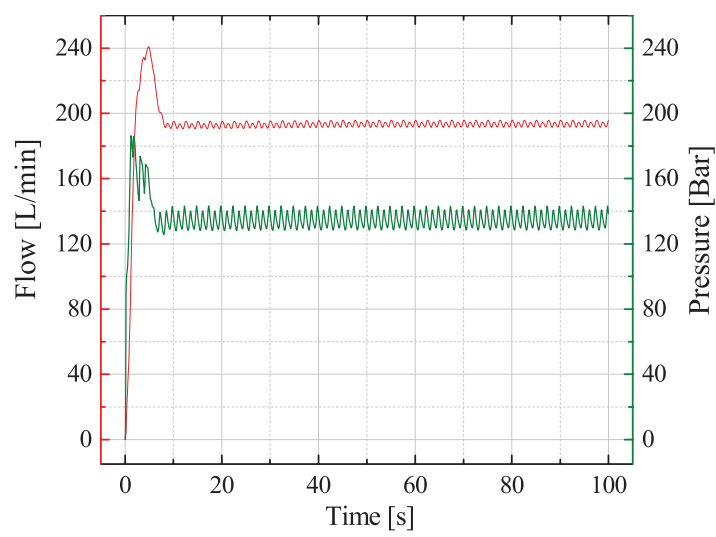

Fig. 5. Motor pressure and flow curves when the cycle is $2.5 \mathrm{~s}$

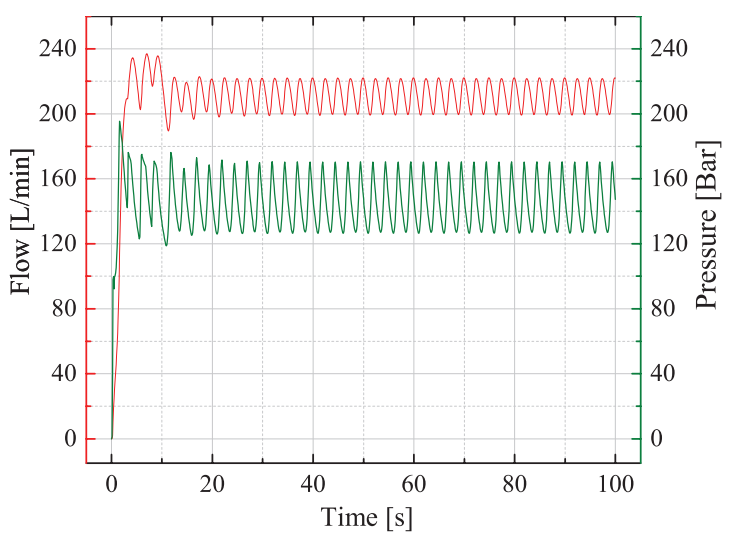

Fig. 6. Motor pressure and flow curves when the cycle is $5 s$

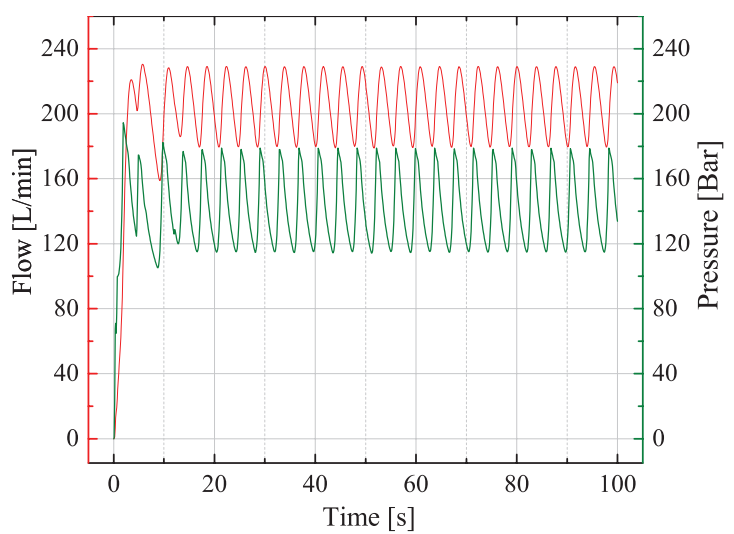

Fig. 7. Motor pressure and flow curves when the cycle is $7.5 \mathrm{~s}$

It can be drawn from the above graph that when the period is $2.5 \mathrm{~s}$, the input fluent of the motor is stable as $190 \mathrm{~L} / \mathrm{min}$, and when the pressure is $130 \mathrm{Bar}$, as the period of the wave increased, the fluctuation scale of the fluent pressure and the efficiency of the system increased, the output stability comes 
down, which makes the followed electric process become difficult.

\section{SIMULATION ANALYSIS ON DIFFERENT AMPLITUDE}

Set analog wave period as $5 \mathrm{~s}$, amplitude of movement of the float as $0.5 \mathrm{~m}, 0.7 \mathrm{~m}, 1 \mathrm{~m}$ to run the simulation model and analyze the output port pressure, flow and efficient curve of the motor, as is shown in Fig. 8-10:

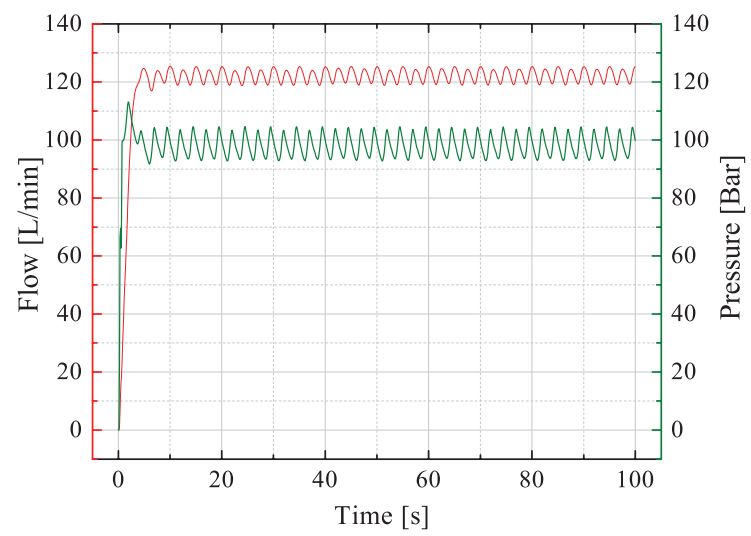

Fig. 8. Motor pressure and flow curves when amplitude is $0.5 \mathrm{~m}$

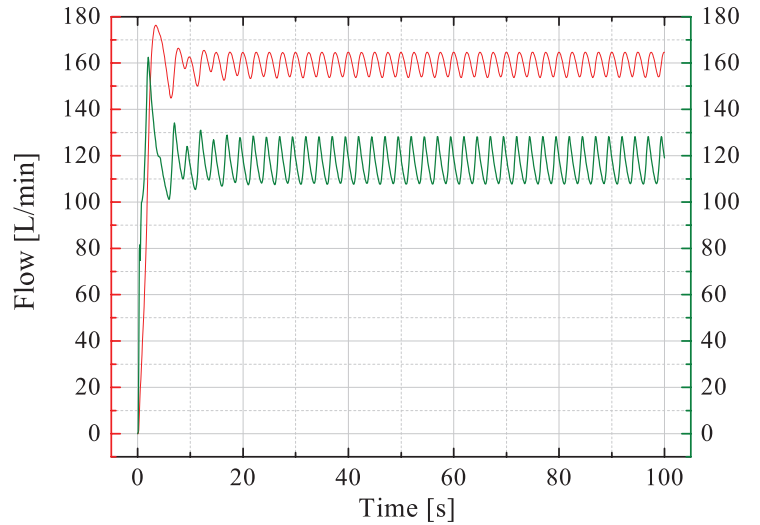

Fig. 9. Motor pressure and flow curves when amplitude is $0.7 \mathrm{~m}$

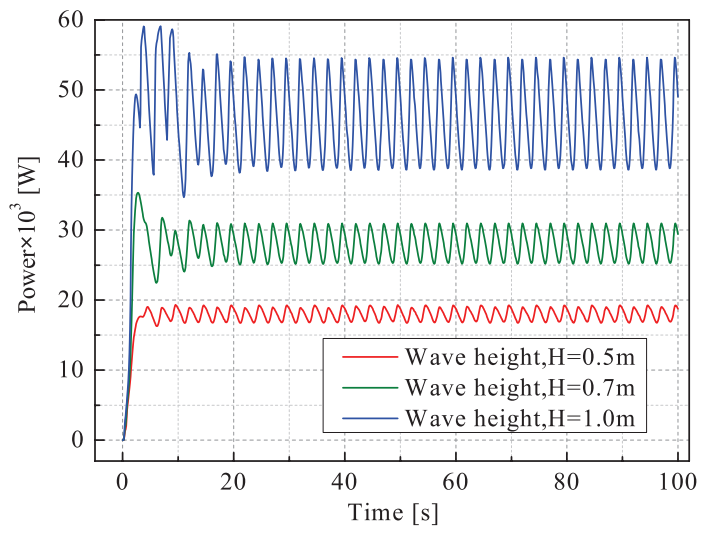

Fig. 10. Power contrast curves with different amplitudes

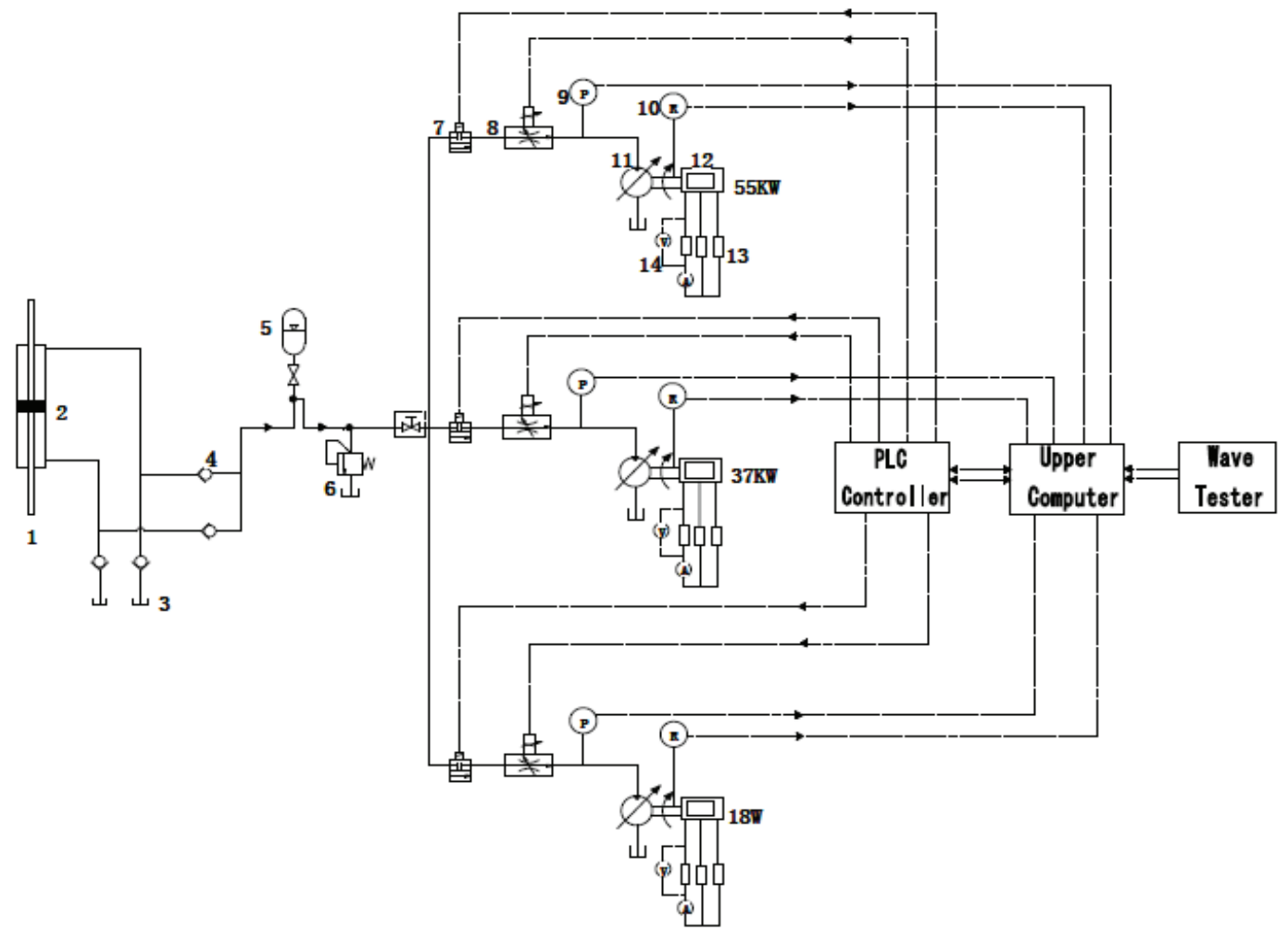

1. hydraulic rod 2. hydraulic cylinder 3. oil tank 4. one-way valve 5. accumulator 6. relief valve 7. Electromagnetic valve 8. speed regulation valve 9. pressure sensor 10. speed sensor 11. motor 12. generator 13 .loads 14. voltage sensor

Fig. 11. Self-adaptive control theory 
According the curve above, when the amplitude is $0.5 \mathrm{~m}$, the system begins to operate, output has concussion, $3 \mathrm{~s}$ later the input flow of motor stable at $120 \mathrm{~L} / \mathrm{min}$, the pressure is 100 Bar, the output efficiency of hydraulic system is $18 \mathrm{~kW}$ :when the amplitude is $0.7 \mathrm{~m}$, the input flow of motor stable at 160 $\mathrm{L} / \mathrm{min}$, the pressure is $120 \mathrm{Bar}$ the output sharp efficiency of hydraulic system is $36 \mathrm{~kW}$ :when the amplitude is $1.0 \mathrm{~m}$, the input flow of motor stable at $210 \mathrm{~L} / \mathrm{min}$, the pressure is 150 Bar the output sharp efficiency of hydraulic system is $55 \mathrm{~kW}$.

With the increase of float movement amplitude, the fluent pressure and efficient are increased, the stability declined and we can see obvious concussion.

\section{OPTIMIZATION DESIGN OF WORK PRINCIPLE}

Conclude from the simulation, the output electric efficiency has great changes in different conditions. In order to solve the problem of the low wave energy conversion efficiency of power generation equipment and the high wave of the start, we propose suitable control technology of wave energy device.

According to the amplitude and period of the wave, we control the electric check valve, using different power rating of the generator at $18 \mathrm{~kW}, 37 \mathrm{~kW}, 55 \mathrm{~kW}$ to realize the suitable control. Thereby expand the wave energy device operating range, so it can automatically adjust the working conditions in the marine changing load, in order to improve the efficiency of the wave energy. The suitable control technology schematic diagram is Fig. 11.

\section{EXPERIMENTAL AND RESULT ANALYSIS}

\section{CONSTRUCTION OF EXPERIMENTAL APPARATUS}

In order to study the impact of wave amplitude and period to stability and efficiency of the output power further, and to verify the simulation results. The land experiment stand is shown in Fig. 12. Shown in the Figure, the hoist pulls the float moves up and down along the buoy to simulate movement of the float in a vertical wave forces, and then to get the hydraulic energy transmission, and finally output electric power.

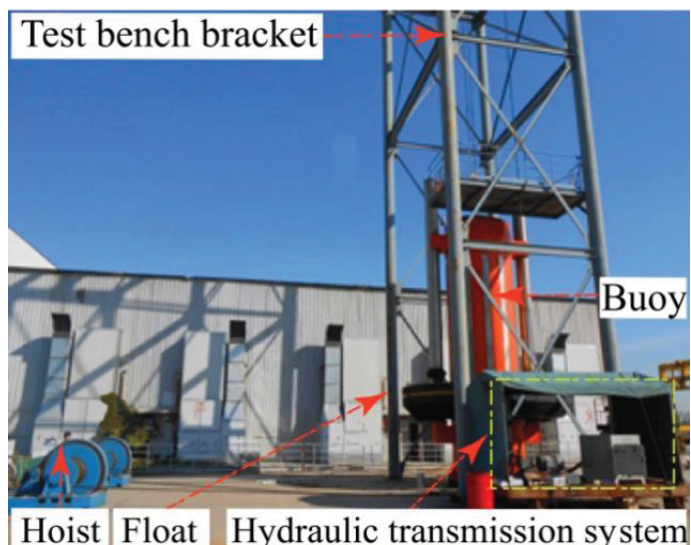

Fig. 12. Experimental apparatus
The following Fig. 13 is an energy delivery system. Through monitoring real-time oceanic state information to control electromagnetic valve. Owing to the low efficiency and poor ability of single generator to adapt the sea state, selection of different rated power generators can solve the problem. Software can collect real-time movement of the float, outlet pressure and flow of the motor, output voltage and current parameters of the generator, which in order to facilitate further analysis.

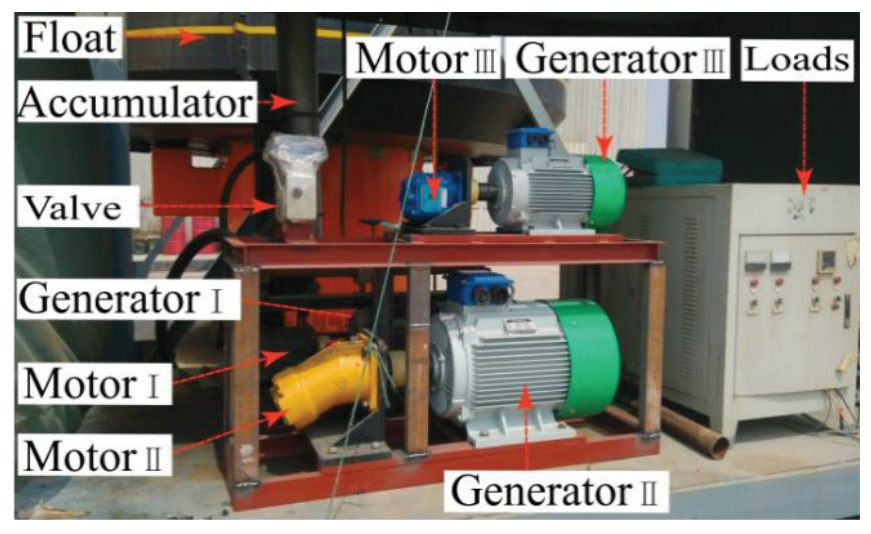

Fig. 13. Energy delivery system

\section{EXPERIMENTAL DATE ANALYSIS}

\section{Effects of different wave periods}

Fig. 14-16 is the input pressure-flow curve of motor, analog movement amplitude of the float is $1 \mathrm{~m}$, periods were taken $2.5 \mathrm{~s}, 5 \mathrm{~s}, 7.5 \mathrm{~s}$

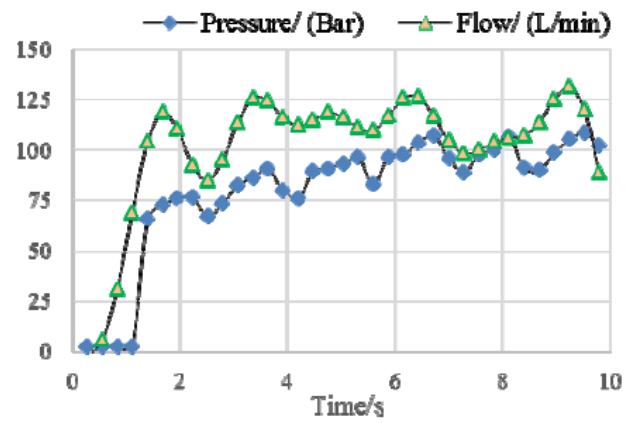

Fig. 14. Motor pressure and flow curve when the cycle is $2.5 \mathrm{~s}$

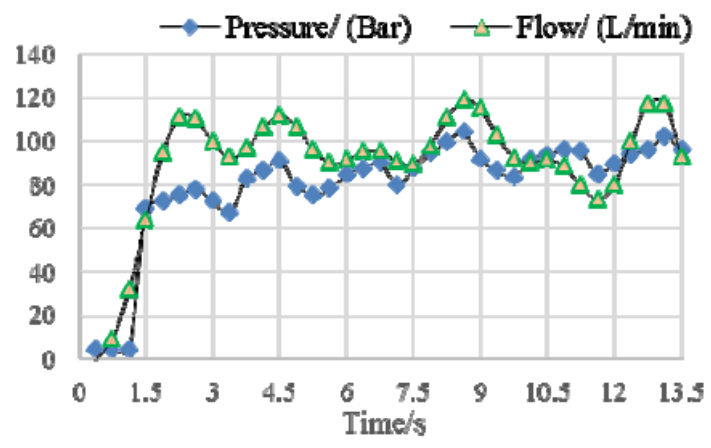

Fig. 15. Motor pressure and flow curve when the cycle is $5 \mathrm{~s}$ 


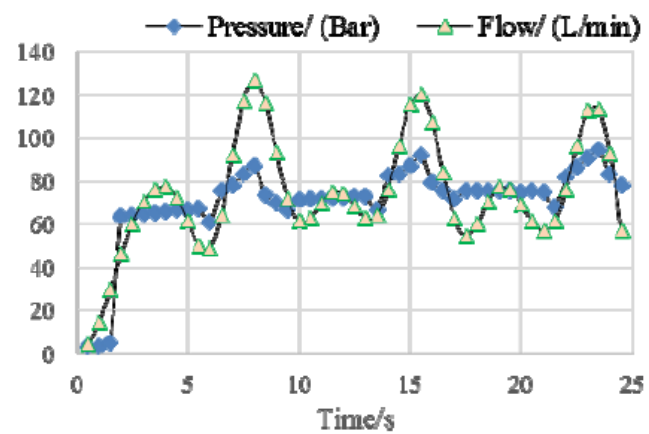

Fig. 16. Motor pressure and flow curve when the cycle is $7.5 \mathrm{~s}$

Analyzing Fig. 14-16 curve we can achieve that: When the period is $2.5 \mathrm{~s}$ and the system starts to work, output is shocked, steady mean flow of imports of the motor is $117 \mathrm{~L} /$ min, pressure is $98.2 \mathrm{Bar}$, When the cycle is $5 \mathrm{~s}$, Steady flow of imports of the motor is $97 \mathrm{~L} / \mathrm{min}$, pressure is $93 \mathrm{Bar}$, When the cycle is $7.5 \mathrm{~s}$, Steady flow of imports of the motor is $68 \mathrm{~L}$ / min, pressure is $78 \mathrm{Bar}$, With increasing wave period, the output flow and pressure of the system is decreasing. When the period is $5 \mathrm{~s}$, the stability is better.

\section{Effects of different wave amplitude}

Fig. 17-20 is the input pressure-flow-power curve of motor, analog movement amplitude of the float is $0.25 \mathrm{~m}, 0.5 \mathrm{~m}, 0.75$ $\mathrm{m}$, the periods were taken $5 \mathrm{~s}$.

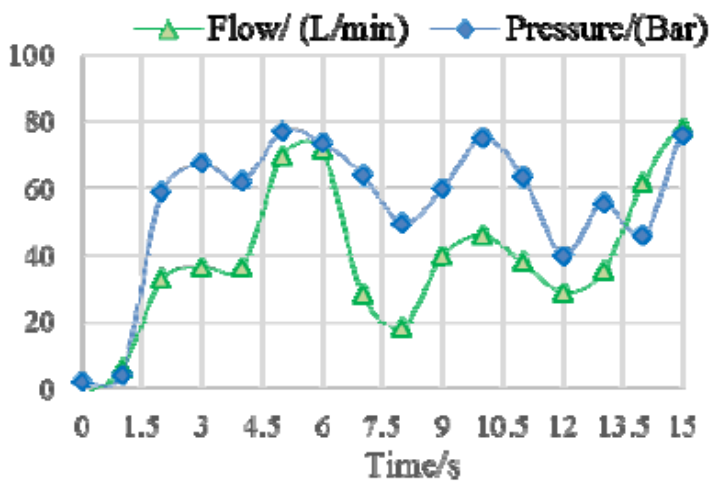

Fig. 17. Motor pressure and flow curves when amplitude is $0.25 \mathrm{~m}$

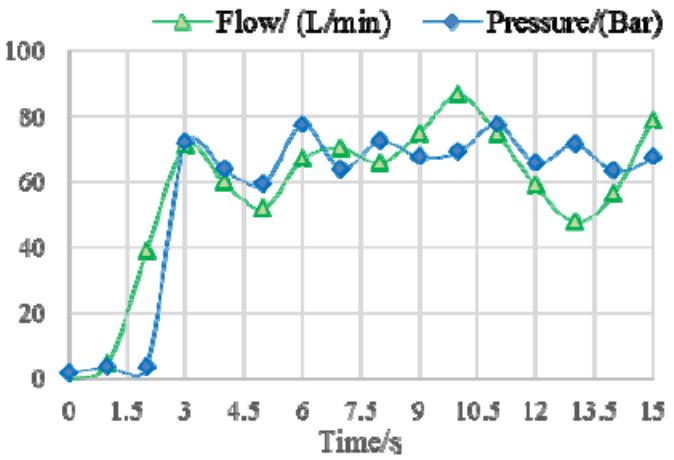

Fig. 18. Motor pressure and flow curves when amplitude is $0.5 \mathrm{~m}$

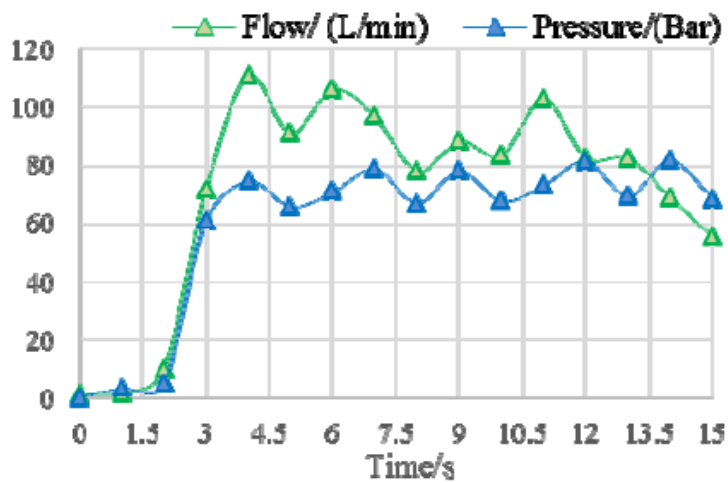

Fig. 19. Motor pressure and flow curves when amplitude is $0.75 \mathrm{~m}$

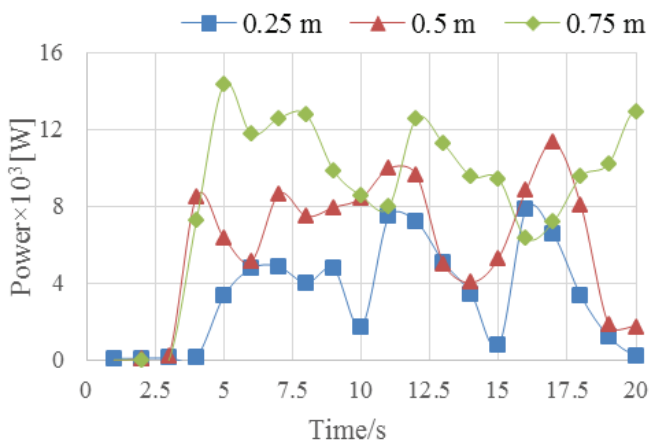

Fig. 20. Power contrast curves with different amplitudes

Analyzing Fig. 17-20 curves we can achieve: When the amplitude is $2.5 \mathrm{~m}$, the system starts to work, output is shocked, steady mean flow of imports of the motor is $40 \mathrm{~L} / \mathrm{min}$, pressure is $60 \mathrm{Bar}$, and the average power is $4.6 \mathrm{~kW}$. When the amplitude is $0.5 \mathrm{~s}$, steady flow of imports of the motor is $60 \mathrm{~L} / \mathrm{min}$, pressure is $65 \mathrm{Bar}$, the average power is $7.5 \mathrm{~kW}$. When the amplitude is $0.75 \mathrm{~s}$, Steady flow of imports of the motor is 95 $\mathrm{L} / \mathrm{min}$, pressure is $71.5 \mathrm{Bar}$, the average power is $10.2 \mathrm{~kW}$. With the wave amplitude increase, the output flow, pressure and power of the system is decreasing, which is consistent with the simulation results.

\section{CONCLUSIONS}

1) The experimental data are coinciding with the simulation curve trend, this manifests the hydraulic system design is feasible and the build of simulation is right.

2) The amplitude of wave has an obvious effect on output efficiency, as the amplitude increase, the output efficiency increased. And the period of wave determines the stability of output efficiency, as the period increased the stability of output efficient decline, and the concussion becomes obviously.

3) Further optimize the designation and guarantee the location and working condition for the waters of the device by simulation and land experiments. Put forward the suitable technology to meet the need of the device in different oceanic conditions to continuous output power and improve the utilization of wave. 


\section{ACKNOWLEDGEMENTS}

This project is partially supported by Renewable Energy Special Foundation of China Oceanic Administration (GHME2010ZC01), Renewable Energy Special Foundation of China Oceanic Administration (SDME2010GC02) and Shandong University Oriented Project "Research on Key Scientific Problems of Marine Resources and the Use (2014QY006)”.

\section{BIBLIOGRAPHY}

1. Shi, H.D., Cao, F,F., Ma, Z., Liu, Z., 2014. Physical Model Experimental Study on the Floating Buoy Wave Power Generator. Journal of Ocean Technology. 33 (4):98-104.

2. Gao, H.T., Li, B., 2015. Establishment of motion model for wave capture buoy and research on hydrodynamic performance of floating-type wave energy converter. Polish Maritime Research. 22 (S1):106-111.

3. Birgersson, K.E., Balaya, P., Yan, J., 2011. Energy Solutions for a Sustainable World. Applied Energy. 90 (1), 1-2.

4. Esteban, M., Leary, D., 2012. Current developments and future prospects of offshore wind and ocean energy. Applied Energy, 90(1):128-136.

5. Yang, L., Hals, J., Moan, T., 2010. Analysis of dynamic effects relevant for the wear damage in hydraulic machines for wave energy conversion. Ocean Engineering. 37(13):1089-1102.

6. Evans, D.V., 1981. Maximum wave-power absorption under motion constraints. Applied Ocean Research 3 (4):200-203.

7. Choi, K.S., Yang, D.S., Park, S.Y., Cho, B.H., 2012. Design and performance test of hydraulic PTO for wave energy converter. International Journal of Precision Engineering \& Manufacturing. 13(5), 795-801.

8. Pizer, D.J., 1993. Maximum wave-power absorption of point absorbers under motion constraints. Applied Ocean Research. 15 (4), 227-234.

9. Vantorre, M., Banasiak, M., Verhoeven, R., 2004. Modelling of hydraulic performance and wave energy extraction by a point absorber in heave. Applied Ocean Research 26, 61-72.

10. Babarit, A., Duclos, G., Clement, A.H., 2004. Comparison of latching control strategies for a heaving wave energy device in random sea. Applied Ocean Research 26, 227-238.

11. Ma, Z., 2013. The Study on Hydrodynamic Performance of Oscillating Floater Buoy Wave Energy Converter [D]. Ocean University of China.

12. Zhang, D.H., Li, W., Lin, Y.G., 2009. Wave energy in China: Current status and perspectives. Renewable energy. 34(10),
2089-2092.

13. Bailey, H., Bryden, I.G., 2011. Influence of a quadratic power take-off on the behavior of a self-contained inertial referenced wave energy converter. Proc. Inst. Mech. Eng. Part M J. Eng. Marit. Environ., 226 (1), 15-22.

14. Zhang, D.X., 2001, Analyzing primary parameters of twinfloater ocean wave generate electricity device and designing it with most optimal geometric shape. Yan shan University. 46-50.

15. Antonelli, M., Baccioli, A., Francesconi, M., Psaroudakis, P., Martorano, L., 2015. Small Scale ORC Plant Modeling with the AMESim Simulation Tool: Analysis of Working Fluid and Thermodynamic Cycle Parameters Influence. Energy Procedia. 81:440-449.

16. Lisowski, J., 2014. Comparison of dynamic games in application to safe ship control. Polish Maritime Research. 21(3), 3-12.

17. Phan, L.K., Stive, M.J.F., 2015. Coastal Mangrove Squeeze in the Mekong Delta. Journal of Coastal Research. 31(2), 233-243.

\section{CONTACT WITH THE AUTHOR}

Yanjun Liu, Ph.D.

lyj111ky@163.com

Mechanical Engineering Institute

Shandong University

Jinan Shandong

250061 China

CHINA 